\title{
Evaluation of enhanced coagulation coupled with magnetic ion exchange (MIEX) in natural organic matter and sulfamethoxazole removals: The role of Al-based coagulant characteristic
}

\author{
Jie $\mathrm{Xu}^{\mathrm{a}}$, Weiying $\mathrm{Xu}^{\mathrm{a}, \mathrm{b}, *}$, Dongsheng Wang ${ }^{\mathrm{b}}$, Guoqing Sang ${ }^{\mathrm{a}}$, Xiaoshuai Yang ${ }^{\mathrm{c}}$ \\ a School of Resources and Environment, University of Ji'nan, No. 336 Nanxinzhuang Western Road, Ji'nan 250022, Shandong, People's Republic of China \\ ${ }^{\mathrm{b}}$ Key Laboratory of Drinking Water Science and Technology, Research Center for Eco-Environmental Science, Chinese Academy of Science, No. 18 Shuangqing Road, Haidian \\ District, Beijing 100085, People's Republic of China \\ 'State Grid Shandong Electric Power Company, No. 150 Jinger Road, Ji'nan 250001, Shandong, People's Republic of China
}

\section{A R T I C L E I N F O}

\section{Article history:}

Received 4 January 2016

Received in revised form 4 May 2016

Accepted 5 May 2016

Available online 6 May 2016

\section{Keywords:}

Enhanced coagulation

Aluminum species

MIEX

Organic matters

\begin{abstract}
A B S T R A C T
The removals of humic acid (HA) and a kind of antibiotic compound by enhanced coagulation (EC) employing various Al-based coagulants with, and without MIEX resin pre-treatment were systematically investigated in this study. A range of techniques were used to evaluate the purification behaviors and mechanisms of the coagulation and MIEX adsorption processes. The experimental results indicated that sufficient dose of Al-based coagulants removed $60-70 \%$ of $\mathrm{HA}$, while traditional $\mathrm{Al}_{2}\left(\mathrm{SO}_{4}\right)_{3}$ (AS) coagulant with low dose of $1.0-5.0 \mathrm{mg} / \mathrm{L}$ coupled with MIEX contributed to a removal rate of $85 \%$. For sole coagulation, $\mathrm{Al}_{13}\left(\left[\mathrm{Al}_{13} \mathrm{O}_{4}(\mathrm{OH})_{24}\left(\mathrm{H}_{2} \mathrm{O}\right)_{12}\right]^{7+}\right)$ only removed $11 \%$ to $<23 \%$ of SMX, while AS and polyaluminum chloride ( $\mathrm{PACl}$ ) contributed to comparable removal of about $40 \%$, indicating charge neutralization was not the major mechanism in SMX removal. The SMX removal could be improved to $68-78 \%$ by MIEX pre-treatment. Dynamic floc sizes during coagulation processes were studied using a laser diffraction particle sizing device. The results demonstrated $\mathrm{Al}_{13}$ led to the smallest flocs, while the adsorption and sweep mechanisms in AS and PACl coagulation processes resulted in larger aggregates. Besides, the pretreatment of MIEX could evidently decrease the floc sizes for all the coagulants.
\end{abstract}

(c) 2016 Elsevier B.V. All rights reserved.

\section{Introduction}

Occurrence of natural organic matter (NOM) as well as synthetic organic compounds (SOCs) in drinking water supplies raises concern over the removal of these compounds by common drinking water treatment processes. NOMs lead to disinfection byproduct (DBPs) by reacting with common disinfectants (e.g., chlorine, ozone, chlorine dioxide, chloramines) [1]. Certain SOCs, encompassing pharmaceuticals and personal care products (PPCPs), pesticides, household chemicals and endocrine disrupting chemicals, have been shown to impose adverse impacts on human, wildlife and aquatic ecosystems [2,3]. Organic contaminants have become an increasing cause of concern for governments and water authorities around the world as they attempt to implement sustainable water treatment practices.

\footnotetext{
* Corresponding author at: School of Resources and Environment, University of Ji'nan, No. 336 Nanxinzhuang Western Road, Ji'nan 250022, Shandong, People's Republic of China.

E-mail address: stu_xuwy@ujn.edu.cn (W. Xu).
}

Chemical coagulation and flocculation in water treatment involves the addition of chemicals to alter the physical state of dissolved and suspended solids and facilitate their removal by sedimentation, which forms an integral part of conventional water treatment scheme. Hydrolyzing $\mathrm{Al}$ (III) salts are presently a kind of widely used inorganic coagulants through the world [4,5]. It is generally believed that the coagulation performances of Al-based coagulants are greatly dependent on the hydrolyzed Al species, which are commonly divided into the monomeric and dimeric species $\left(\mathrm{Al}_{\mathrm{a}}\right)$, the species with medium molecular weight $\left(\mathrm{Al}_{13} / \mathrm{Al}_{\mathrm{b}}\right)$ and the colloidal or solid-phase species $\left(\mathrm{Al}_{\mathrm{C}}\right)$ [6,7]. Yan et al. [8] observed that $\mathrm{Al}_{\mathrm{a}}$ shows a strong ability to react with some unsatisfied coordinate bonds of organic matter to facilitate particle and DOC removal, although it is the most unstable species in the primary coagulants. Besides, flocs formed by $\mathrm{Al}_{\mathrm{c}}$ were found to be larger than those by other species, which is favor of the settling efficiency. Comparatively, most researchers claimed that prehydrolyzed $\mathrm{Al}_{\mathrm{b}}$ with high positive charge shows applicability within broad $\mathrm{pH}$ and could destabilize particles more efficiently $[8,9]$. It has been proven that hydrophobic and high molar mass 
fractions of NOMs can be efficiently removed by enhanced coagulation (EC) [10]. However, one of the main disadvantages of EC is increased chemical addition and the production of more sludge that must be disposed. In addition, it was reported that coagulation is not effective for some synthetic organic matters due to their physico-chemical properties, such as antibiotic and other small molecules, especially those present at trace concentrations [1113].

Recently, using magnetic ion exchange resin (MIEX) to remove organic or inorganic matter from water has become an increasing cause of concern for researcher as they attempt to respond to the organic matter removal challenges. The MIEX has a great deal of advantage such as small pore size [14,15], magnetic properties, high density and settlement rate due to magnetized iron oxide incorporated into the polymer matrix, providing much greater external surface area that allows rapid sorption kinetic and a recovery rate of greater than $99.9 \%$ as long as the regeneration method is appropriate [16,17]. Up to now, many researches have been carried out on the combination of MIEX with traditional treatment technique and it has been proved that the MIEX, as a pre-treatment process, could significantly improve the efficiency of coagulation in removing dissolved organic matter, phosphorus and hardness [18-20]. However, the performances of MIEX combined with various Al-based coagulants containing different $\mathrm{Al}$ species distributions have been rarely investigated. In addition, very little data are currently available on the relationship between Al species distribution and the characteristics of organic matters, especially those existed at trace concentrations such as antibacterial and antifungal drugs. And the mechanism on how conclusion is involved in coagulation remains not yet clearly understood.

This paper, therefore, was conducted to compare the EC, MIEX treatment and their coupled process in the removals of organic matters with different properties. It enabled an extended evaluation of the impact of MIEX resin on organic matter removal by comparing the performance of the three processes. Research related to different aluminum species was conducted by employing various Al-based coagulants, including aluminum sulfate (AS), polyaluminum chloride ( $\mathrm{PACl}$ ) and $\mathrm{Al}_{13}$ coagulants. And the performances of different coagulants in various organic matters removals were comparatively studied. Application of MIEX resin prior to coagulation was carried out for three coagulants and the effect of MIEX on the coagulation process was investigated mainly through the dynamic monitor on the coagulation process and the assessment of floc characteristics under different MIEX adsorption/coagulation conditions.

\section{Materials and methods}

\subsection{Preparation and characterization of coagulants}

Three Al-based coagulants were used in this study. AS was prepared by diluting pre-determined $\mathrm{Al}_{2}\left(\mathrm{SO}_{4}\right)_{3} \cdot 12 \mathrm{H}_{2} \mathrm{O}$ (Sinopharm Chemical Reagent Co., Ltd., Beijing, China) into distilled water. $\mathrm{PACl}$ coagulant with the total concentration of $0.5 \mathrm{~mol} / \mathrm{L}$ was prepared using solid-solid mixing method and more detail could be found in our previous paper [21]. The $\mathrm{Al}_{13}$ coagulant was purified from $\mathrm{PACl}$ using precipitation with ethanol and acetone method and $\mathrm{SO}_{4}^{2-} / \mathrm{Ba}^{2+}$ displacement method according to $\mathrm{Xu}$ and Gao [22] and Shi et al. [23].

The total Al concentration was measured by ICP-OES (Perkin Elmer, Model Optima 7000 DV, USA). The Al species distributions of coagulants were determined by the ${ }^{27} \mathrm{Al} \mathrm{NMR}$ (nuclear magnetic resonance) spectroscopy to provide speciation based on structure symmetry of specie and Al-Ferron timed complexation spectrophotometer with ferron reagent to provide speciation based on chem-
Table 1

The $\mathrm{Al}$ species distributions of different Al-based coagulants.

\begin{tabular}{llccr}
\hline Method & Coagulants & $\mathrm{Al}_{\mathrm{a}}(\%)$ & $\mathrm{Al}_{\mathrm{b}}(\%)$ & $\mathrm{Al}_{\mathrm{c}}(\%)$ \\
\hline${ }^{27} \mathrm{Al} \mathrm{NMR}$ & $\mathrm{AS}$ & 98.6 & 0.2 & 0.2 \\
& $\mathrm{PACl}$ & 14.5 & 41.9 & 43.6 \\
& $\mathrm{Al}_{13}$ & 4.4 & 91.2 & 4.4 \\
Al-Ferron & $\mathrm{AS}$ & 99.4 & 0.4 & 0.2 \\
& $\mathrm{PACl}$ & 15.0 & 41.7 & 43.3 \\
& $\mathrm{Al}_{13}$ & 4.3 & 91.3 & 4.4
\end{tabular}

ical reactivity. Table 1 lists the Al species distributions of three coagulants. It could be found that, $\mathrm{AS}$ and $\mathrm{Al}_{13}$ are mainly composed of monomeric species $\left(\mathrm{Al}_{\mathrm{a}}\right)$ and medium polymer species $\left(A l_{b}\right.$ ), respectively; while all the $A_{a}, A l_{b}$ and $A_{c}$ species (sol or gel $\left.\mathrm{Al}(\mathrm{OH})_{3}\right)$ could be detected in the $\mathrm{PACl}$ solution.

\subsection{Preparation of water samples}

In this study, humic acid (HA), which is believed as the most important and common constituents of natural organic matter in surface water [24], was chosen to prepare the NOM water sample. HA stock solution was prepared by dissolving $1.0 \mathrm{~g}$ of HA (Aladdin, Shanghai, China) in deionized water and diluting to $1 \mathrm{~L}$. Meanwhile, $4.2 \mathrm{~g} \mathrm{NaHCO}_{3}$ was added to provide a certain buffer capacity and ionic strength. Then the stock solution was stirred continuously for $5 \mathrm{~h}$. The test water was prepared by dissolving $10.0 \mathrm{~mL}$ of stock solution into $1 \mathrm{~L}$ of deionized water. The molecular weight (MW) distribution of HA, measured using performance size exclusion chromatography (HPSEC) method and detected by high performance liquid chromatography system (Waters 1525, Waters, USA), was $400 \mathrm{Da}-5 \mathrm{kDa}$. Sulfamethoxazole (SMX) as a kind of antibacterial and antifungal drugs is among the most frequently detected antibiotics [25] and was employed in this study to represent the SOC compounds in water resources. The structural formula of SMX is shown in Fig. 1. The SMX stock solution $(1.0 \mathrm{~g} / \mathrm{L})$ was prepared using the deionized water with a very small amount of methanol and the SMX test water was diluted to the concentration of $1.0 \mathrm{mg} / \mathrm{L}$.

\subsection{Jar tests and adsorption procedure}

Coagulation tests were performed using a conventional jar-test apparatus (ZR4-6, Zhongrun Water Industry Technology Development Co. Ltd., China) with $50 * 40 \mathrm{~mm}$ flat paddle impellers and $1 \mathrm{~L}$ cylindrical beakers. Predetermined amount of coagulant was added at the start of coagulation; thereafter, $1.5 \mathrm{~min}$ of rapid mixing at $200 \mathrm{rpm}(\mathrm{rpm})$ was applied, followed by $15 \mathrm{~min}$ of slow stirring at $40 \mathrm{rpm}$. Then after $30 \mathrm{~min}$ of quiescent settling, sample

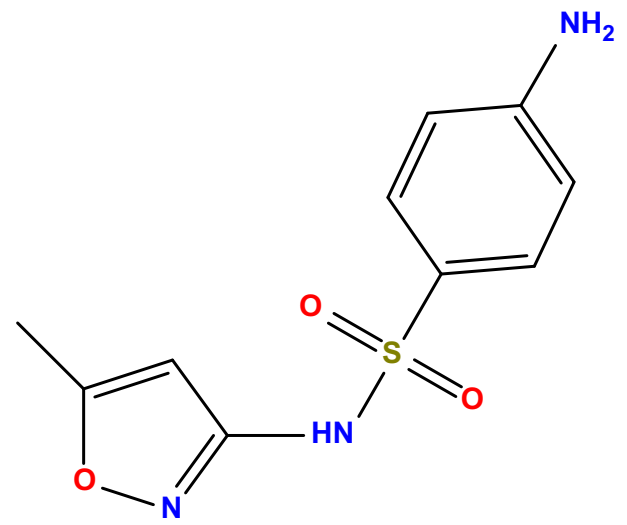

Fig. 1. Chemical structural formula of SMX 
was collected from $2 \mathrm{~cm}$ below the surface and passed through a $0.45 \mu \mathrm{m}$ glass filter paper for DOC measurement (TekmarDohrman Co., Phoenix, AZ). A small amount of sample was taken immediately after the $1.5 \mathrm{~min}$ of rapid mixing to determine the zeta potential (Malvern, Zetasizer 2000, U.K.).

Batch adsorption experiments were performed in beakers containing $1000 \mathrm{~mL}$ of HA and SMX solutions with initial concentrations of $10.0 \mathrm{mg} / \mathrm{L}$ and $1.0 \mathrm{mg} / \mathrm{L}$, respectively. Appropriate amount of MIEX resin was added to the beaker, and the mixed solution was stirred by an agitation speed of $150 \mathrm{rpm}$, followed by $30 \mathrm{~s}$ of settlement. Sampling was conducted at the end of sedimentation. All the experiments were carried out in triplicate and the average values were reported herein.

\subsection{Analytical methods of SMX}

SMX concentration was determined by the ultra-high performance liquid chromatography/tandem mass spectrometer (ACQUITY UPLC/Quattro Premier XE, Waters Co, USA) equipped with an electrospray ion source (Micromass, Manchester, UK). The instrument was operated using an electrospray (ESI) source in positive mode with the following parameters: $3.4 \mathrm{kV}$ capillary voltage, $25 \mathrm{~V}$ cone voltage, $344^{\circ} \mathrm{C}$ desolvation temperature, and $600 \mathrm{~L} / \mathrm{h}$ desolvation gas (nitrogen $>99.999 \%$ ) flow. The operation condition for the source temperature were $120^{\circ} \mathrm{C}$ using an isocratic mobile phase of formic acid $0.1 \%$ /acetonitrile $(20: 80, \mathrm{v} / \mathrm{v})$ at a flow rate of $0.2 \mathrm{~mL} / \mathrm{min}$. Multiple reaction monitoring (MRM) mode was applied for the quantitation with the parameters that parent ion, daughter ion, retention time and the inter-channel delay time are $254.009(\mathrm{~m} / \mathrm{z}), 107.318(\mathrm{~m} / \mathrm{z}), 9.5 \mathrm{~min}$ and $0.5 \mathrm{~min}$, respectively. Data acquisition was performed using MassLynx V4.1 software with the Quanlynx program (Waters).

\subsection{On-line measurement of floc size}

A continuous laser diffraction instrument (Mastersizer 2000, Malvern, U.K.) was used to measure the dynamic floc size as the coagulation proceeded. The suspension was monitored through the optical unit of the Mastersizer and transferred back into the jar by a peristaltic pump (LEAD-1, Longer Precision Pump, Baoding, China) with a $5 \mathrm{~mm}$ internal diameter tube at a flow rate of $10 \mathrm{~mL} /$ min. The size measurements were taken every $30 \mathrm{~s}$ for the duration of the jar test. In addition, the inflow and out flow tubes were placed opposite one another at a depth just above the impeller in the holding ports. More detail has been reported in full in other paper [26].

\section{Results and discussion}

\subsection{Removal of HA with different Al-based coagulants/MIEX resin}

An initial series of tests were undertaken to establish an optimal coagulant quantity for subsequent tests. HA removal was investigated in terms of DOC removal efficiency and the coagulant dosage ranged from $1.0 \mathrm{mg} / \mathrm{L}$ to $10.0 \mathrm{mg} / \mathrm{L}$. As illustrated in Fig. 2 , the curves of coagulation efficiency for three Al-based coagulants, i.e. $\mathrm{AS}, \mathrm{PACl}$ and $\mathrm{Al}_{13}$ were roughly similar, which showed sharp increase within the dose of $1.0-4.0 \mathrm{mg} / \mathrm{L}$. The increase turned out to be slight with further increasing doses $(5.0-10.0 \mathrm{mg} / \mathrm{L}$ ) and finally reached the plateaus of $60-70 \%$ of $\mathrm{DOC}$ removals. $\mathrm{Al}_{13}$ contributed to higher removal efficiencies at low dosages of 1.0$2.0 \mathrm{mg} / \mathrm{L}$ than AS and PACl, while the difference turned out to be neglectable at higher dosage range of $3.0-10.0 \mathrm{mg} / \mathrm{L}$. This could be ascribed to the different charge neutralization abilities of coagulants, which was believed to be the major mechanism in pollutant
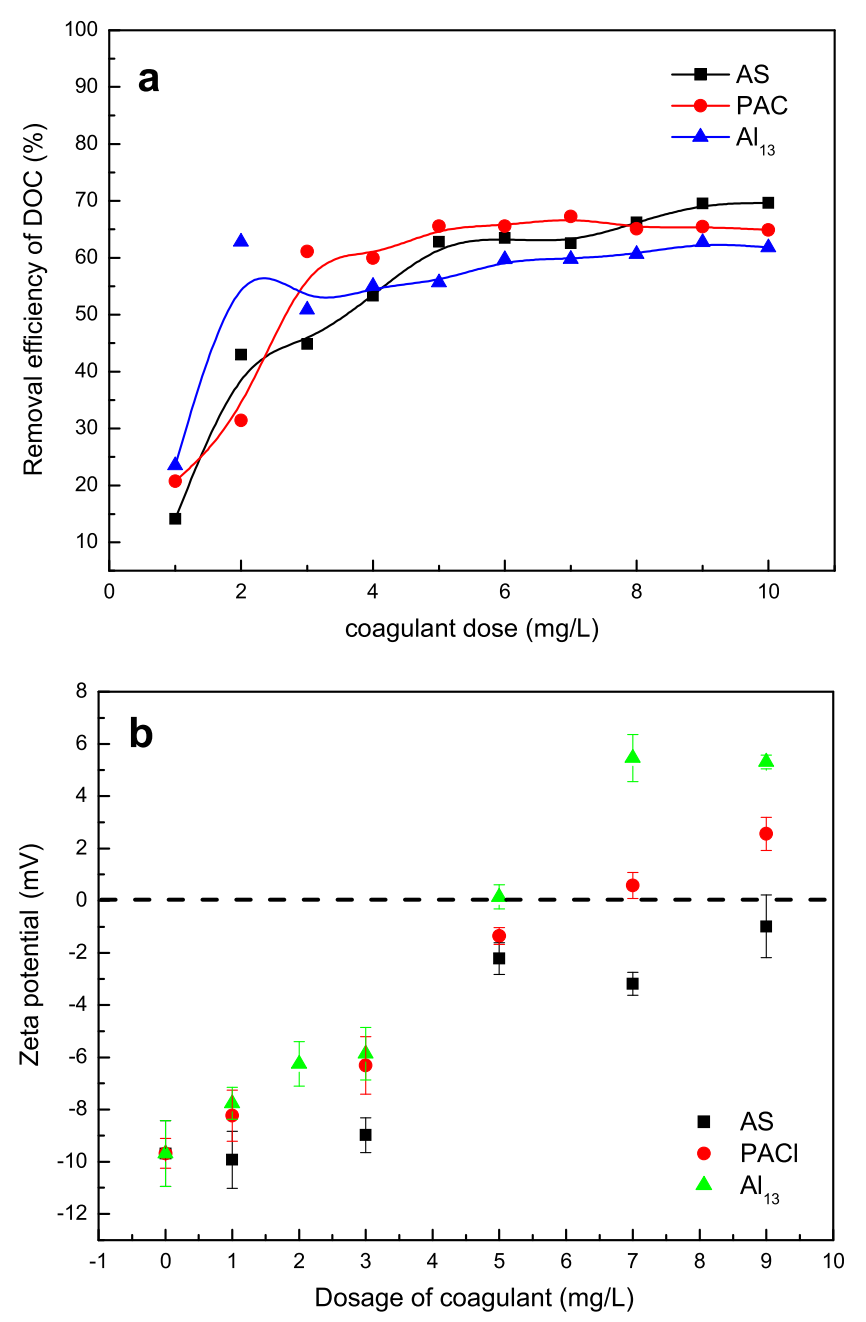

Fig. 2. Effects of coagulant dosage on (a) HA removal efficiency and (b) zeta potentials (the doses of $\mathrm{AS}, \mathrm{PACl}$ and $\mathrm{Al}_{13}$ ranged from 1.0 to $10.0 \mathrm{mg} / \mathrm{L}$ as $\mathrm{Al}$ ).

removal at low coagulant concentrations [27]. Zeta potential data for different coagulation systems were measured (Fig. 2(b)) and the results demonstrated that coagulation systems with $\mathrm{Al}_{13}$ present highest zeta potentials, indicating the best neutralization ability of the pre-hydrolyzed $\mathrm{Al}_{13}$. Under the same dosage, zeta potential was in the sequence of $\mathrm{Al}_{13}>\mathrm{PACl}>\mathrm{AS}$, which had a good correlation with the content of $\mathrm{Al}_{\mathrm{b}}$ (as shown in Table 1). This is consistent with the published literature which indicates that the active $\mathrm{Al}_{13}$ species in the pre-hydrolyzed aluminum salts is the most highly charged [28]. It should be noted that zeta potentials for $\mathrm{PACl}$ and $\mathrm{Al}_{13}$ became positive as their concentrations increased to $5.0 \mathrm{mg} / \mathrm{L}$ and above, which might lead to re-stabilization of the colloidal matters. However, the data in Fig. 2(a) proved constantly effective $\mathrm{DOC}$ removals by $\mathrm{PACl}$ and $\mathrm{Al}_{13}$ in the dose range of 5.0$10.0 \mathrm{mg} / \mathrm{L}$, indicating charge neutralization was not the unique coagulation mechanism. Other mechanisms, including interparticle bridging and adsorption might also play significant roles in HA removals. It has been recognized that monomeric Al readily forms a large amount of amorphous aluminum hydroxide [29], and consequently when AS solution, containing most monomeric $\mathrm{Al}$, was dosed into the solution at a sufficiently high concentration (above $4.0 \mathrm{mg} / \mathrm{L}$ ), organic matters could be efficiently enmeshed in the amorphous precipitates.

Preliminary jar tests were also conducted using the MIEX resin to evaluate its performance in DOC removal. The results shown in Fig. 3 illustrated that both the resin dose and contact time had 


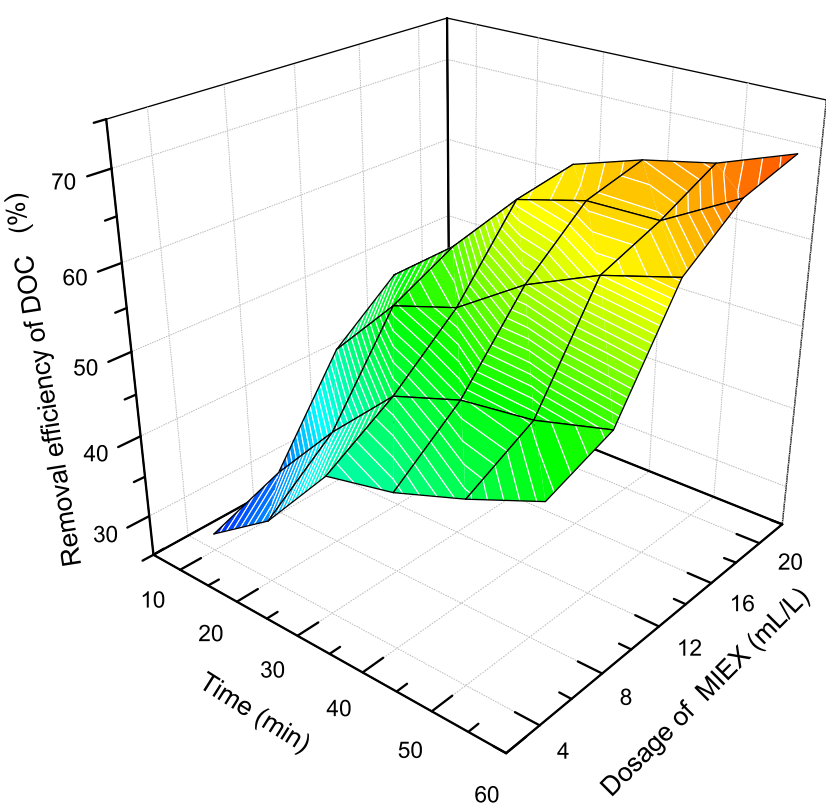

Fig. 3. Variations of HA removals under different MIEX resin dosages (4.0-20.0 mL L) and contact time (10-60 $\mathrm{min})$.

significant impacts on HA removal, which present an evidently positive correlation. Residual HA concentration decreased as the resin dose and react time increased because more surface area (exchange sites) and adsorption time were provided and accordingly, more organic carbon was removed. Consequently, a maximum HA removal efficiency of about $70 \%$, which was comparable with that by sole coagulation, was obtained at the highest resin dosage of $20.0 \mathrm{~mL} / \mathrm{L}$ as well as the longest mixing time of $60 \mathrm{~min}$ used in this study. Ion exchange resins are very proficient at removing humic substances from water supplies as a large fraction of NOM can be characterised as anionic polyelectrolytes [30]. Previous research on the application of MIEX resin for organic matter control has shown that most dissolved organic matter and $U_{254}$ removal occurs in the first $15-30 \mathrm{~min}$ [31-33]. It was found 30 min of mixing allows easily removable hydrophobic and hydrophilic NOM to exchange with chloride ion without allowing significant interparticle adsorption of NOM on the resin to occur. By allowing ion exchange to dominate over interparticle adsorption as the main mechanism for NOM removal, the resin can be regenerated more easily. Therefore considering the cost and operational feasibility, the contact time was fixed at $30 \mathrm{~min}$ and two MIEX resin dosages of 4 and $12 \mathrm{~mL} / \mathrm{L}$, representing the low and high resin dose, respectively, were adopted in the following experiments to comparatively evaluate the behaviors of MIEX/coagulation hybrid process in organic matter removals.

\subsection{HA removal by combined MIEX-coagulation process with different aluminum coagulants}

Fig. 4 illustrates the effects of MIEX pre-treatment on the performances of three different coagulants in HA removals. It could be found that the MIEX unit significantly increased the HA removal rates by coagulations, especially at the high MIEX resin dosage of $12 \mathrm{~mL} / \mathrm{L}$. After $4 \mathrm{~mL} / \mathrm{L}$ of MIEX pre-treatment, HA removal increased initially $(1-6 \mathrm{mg} / \mathrm{L})$ with the AS concentration and then reached a steady rate of $73 \%$; while for $\mathrm{PACl}$ and $\mathrm{Al}_{13}$, more constant removal rate (around 75\%) was attained in the whole coagulant dose investigated in this study. When $12 \mathrm{~mL} / \mathrm{L}$ of MIEX was applied for the pre-treatment, the removal curves were obviously different with those by low dose of MIEX. The DOC removal efficiencies remained in the range of $58-75 \%$ and $69-81 \%$ for $\mathrm{Al}_{13}$ and $\mathrm{PACl}$ coagulation, respectively. AS with $12 \mathrm{~mL} / \mathrm{L}$ of MIEX pretreatment gave the best DOC removal of around 85\% across the coagulant dose employed in this study. It is interesting to note that the best removal efficiencies were achieved at the lowest dose of $1.0 \mathrm{mg} / \mathrm{L}$, for all the three kinds of coagulants. As the coagulant amount increased, varying degrees of declines but with small scale were found for different coagulation systems. On the whole, HA removal efficiency was in the following order of $\mathrm{AS}>\mathrm{PACl}>\mathrm{Al}_{13}$. Removals greater than $75 \%$ were considered statistically significant. It could be consequently concluded that low concentration of MIEX $(4 \mathrm{~mL} / \mathrm{L})$ coupled with $\mathrm{PACl}$, and high MIEX dose of $12 \mathrm{~mL} / \mathrm{L}$ combined with conventional coagulant, i.e. AS, appeared to best suited to removing the organic matters with mid and high molecular weight (MW), even at a low dosage of $1.0 \mathrm{mg} / \mathrm{L}$. That is to say, MIEX resin could remarkably reduce the amount of coagulant required for HA removal for all three coagulants. MIEX eliminated an evident portion of the coagulant demand in several ways, the most important of which was a significant reduction in organic matter concentration. Moderate HA removal efficiency of $50 \%$ required the $\mathrm{AS}, \mathrm{PACl}$ and $\mathrm{Al}_{13}$ amount of about 4.0, 3.0 and $2.0 \mathrm{mg} / \mathrm{L}$ for sole coagulation; while for the solution treated by
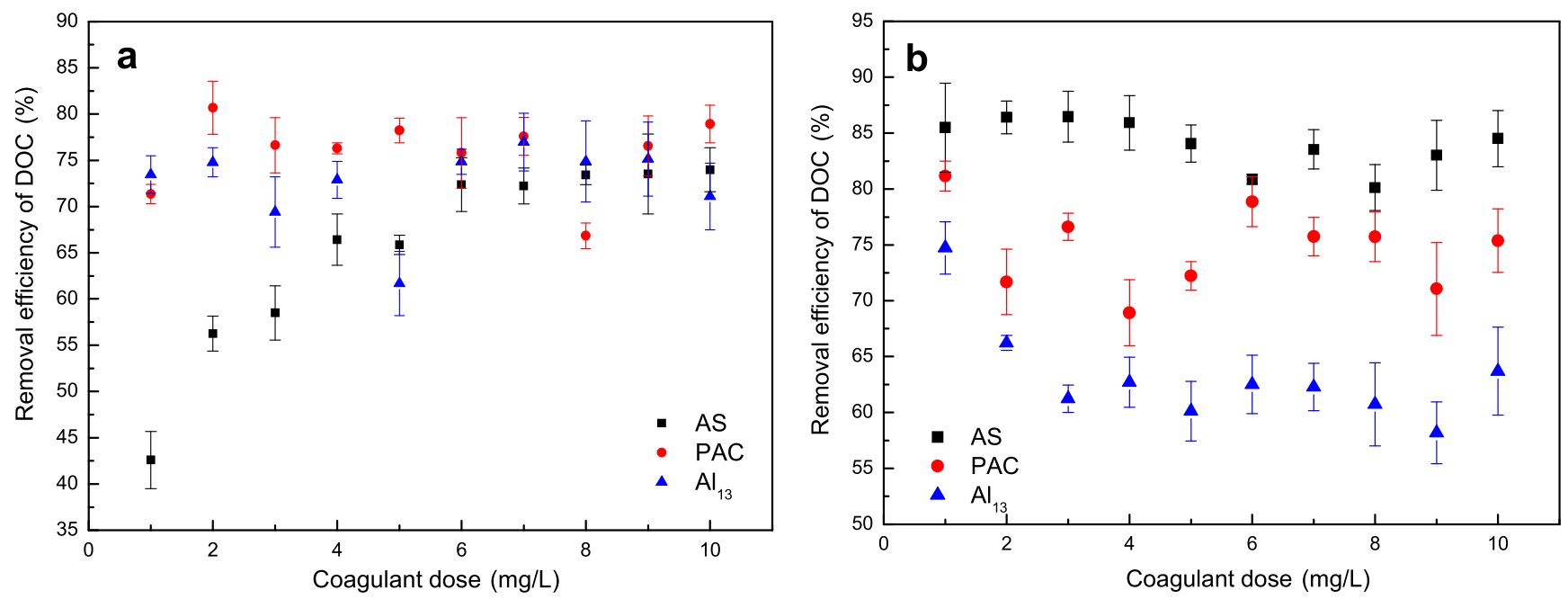

Fig. 4. Effect of coagulant dosage on HA removal after pre-treatment of MIEX resin at the dose of (a) $4 \mathrm{~mL} / \mathrm{L}$ and (b) $12 \mathrm{~mL} / \mathrm{L}$. 

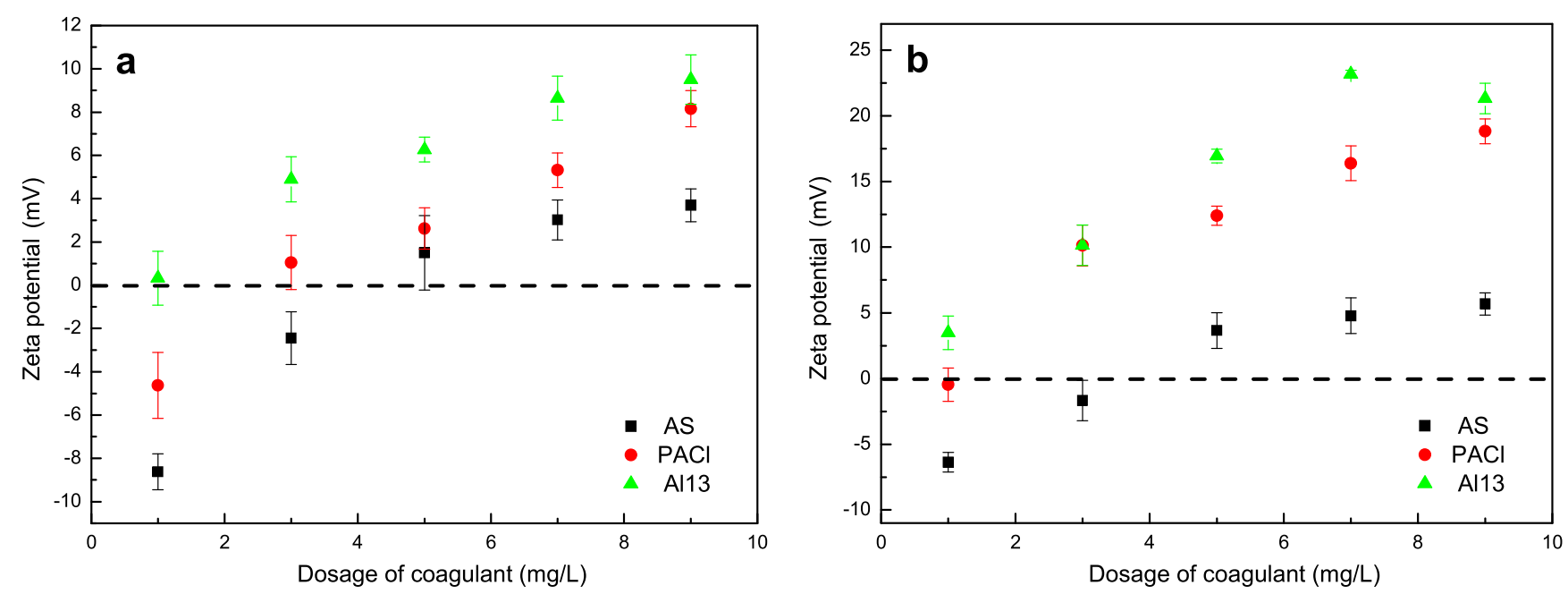

Fig. 5. Zeta potentials for different coagulation systems after (a) $4 \mathrm{~mL} / \mathrm{L}$ and (b) $12 \mathrm{~mL} / \mathrm{L}$ of MIEX pre-treatment as a function of coagulant dose (1.0-10.0 mg/L as Al).

$4.0 \mathrm{~mL} / \mathrm{L}$ of MIEX, the demand chemical concentration could be reduced to $2.0 \mathrm{mg} / \mathrm{L}$ for AS, and for the pre-hydrolyzed coagulants, $70 \%$ of removal rate was achieved even at the dose of $1.0 \mathrm{mg} / \mathrm{L}$.

As illustrated in Fig. 5, zeta potentials of different coagulation systems pre-treated by MIEX resin were comparatively tested, which were found evidently higher than those without MIEX treatment (Fig. 2). For PACl and $\mathrm{Al}_{13}$, zeta potentials turned to be positive at the doses of $1.0-3.0 \mathrm{mg} / \mathrm{L}$ and as the coagulant amount increased, charge reversal occurred, where the remainder HA colloids with positive charge tended to repel each other and definitely hindered the generation of flocs. This was the reason why $\mathrm{PACl}$ and $\mathrm{Al}_{13}$ performed inferiorly than $\mathrm{AS}$ in combination with sufficient dose of MIEX.

\subsection{NOM floc characteristics}

The laser diffraction instrument used in the studies reported particle size as an equivalent volumetric diameter $\left(d_{50}\right)$. The developments of floc size during the period of coagulations by AS, PACl and $\mathrm{Al}_{13}$ were measured at the optimum chemical dosage of $5.0 \mathrm{mg} / \mathrm{L}$ and a lower dose of $2.0 \mathrm{mg} / \mathrm{L}$, by which the HA water could not be coagulated well, was also employed in the tests for comparison. It was observed from Fig. 6(a) that the $d_{50}$ values for all the coagulation processes increased initially with coagulation time and then reached the plateau. As the largest flocs were formed, the number of primary particles decreased to a minimum before the coagulation reached the steady-state, which resulted in the significant decrease in the collision rate and the increase in the breakage rate [34]. At the dosage of $2.0 \mathrm{mg} / \mathrm{L}$, the steady-state sizes of flocs followed the order of AS $(108 \mu \mathrm{m})<\mathrm{PACl}(196 \mu \mathrm{m})<\mathrm{Al}_{13}$ $(301 \mu \mathrm{m})$. The pre-hydrolyzed coagulants were found to contribute to approximately double or triple the size of aggregates formed by AS. When the coagulant was dosed at a sufficient dose of $5.0 \mathrm{mg} / \mathrm{L}$, the final floc sizes turned out to be much larger, which were $573 \mu \mathrm{m}, 397 \mu \mathrm{m}$ and $330 \mu \mathrm{m}$ for the $\mathrm{AS}, \mathrm{PACl}$ and $\mathrm{Al}_{13}$ coagulation systems. The results illustrated that the growth of the flocs could be improved with higher dosage of Al-based salts during coagulation, where sweep flocculation presumably played important role in the HA coagulation. Floc size values formed by $5 \mathrm{mg} / \mathrm{L}$ of AS were found fluctuated more obviously than those in the other coagulation systems, which could be probably due to the large size values of flocs leading to slightly bigger errors. Besides, it was worthwhile to notice that $\mathrm{Al}_{13}$ let to no appreciable varying of floc sizes with the increase of its concentration, this could be ascribed to the better charge neutralization ability and stable structure of $\mathrm{Al}_{13}$. Zeta potentials for coagulation with 2.0 and $5.0 \mathrm{mg} / \mathrm{L}$ of $\mathrm{Al}_{13}$ were -6.25 and $0.15 \mathrm{mV}$, respectively. Previous research of $\mathrm{Yu}$ et al. [35] revealed that effective onset of coagulation corresponded with dosage where zeta potential had risen to about $-8 \mathrm{mV}$, so it could be speculated that $2.0 \mathrm{mg} / \mathrm{L}$ of $\mathrm{Al}_{13}$ was sufficient enough to destabilize the colloids efficiently through charge neutralization.

In a further series of tests, floc sizes of coagulation systems pretreated by 4 and $12 \mathrm{~mL} / \mathrm{L}$ of MIEX resin and subsequently $5.0 \mathrm{mg} / \mathrm{L}$ of coagulants were measured as shown in Fig. 6(b) and (c), respectively. It was evident that the pre-treatment of MIEX resin decreased the floc sizes formed in the following coagulation processes. For the solution treated by $4 \mathrm{~mL} / \mathrm{L}$ MIEX, all the three aluminum coagulants resulted in flocs with sizes lower than $100 \mu \mathrm{m}$. When a higher dose of MIEX $(12 \mathrm{~mL} / \mathrm{L})$ was dosed for the treatment, the major peaks of the floc size distributions were found to shift to the left, indicating further decrease of the floc size. The $d_{50}$ values of flocs for the three coagulation systems were between 40 and $60 \mu \mathrm{m}$. This might be ascribed to the effective removing of HA by MIEX resin, which removed the HA considerably and thus less initial tiny particles were left to colloid and aggregate into large flocs. The less residual organic matters, the more obstruction of the aggregation of tiny particles. The pretreatment effects of MIEX essentially depended on the ion exchange and adsorption mechanisms rather than aggregations.

\subsection{Comparison of SMX removals by different Al-based coagulants and MIEX resin}

The properties of organic matters were believed to have considerable influence on their removal performances by coagulation and adsorptive processes [25]. The antibiotic SMX solution, which presents entirely different physicochemical property with natural organic matters, was comparatively treated by coagulations and MIEX in this study. It could be found from Fig. 7(a) that over the range of aluminum coagulant dosage applied in this investigation (1.0-9.0 $\mathrm{mg} / \mathrm{L}), \mathrm{SMX}$ listed on the $\chi$-axis were ranked from lowest percentage removal (left) to highest removal (right). At the low dosage of $1 \mathrm{mg} / \mathrm{L}$, removal of the antibiotic ranged between $9 \%$ and $14 \%$, and increasing coagulant dosage definitely improved SMX percentage removals. Dosage of $9 \mathrm{mg} / \mathrm{L}$ effectively removed about $40 \%, 39 \%$ and $22 \%$ of SMX for $\mathrm{AS}, \mathrm{PACl}$ and $\mathrm{Al}_{13} . \mathrm{Al}_{13}$ present the least efficiency, while the trends in percentage removals were 

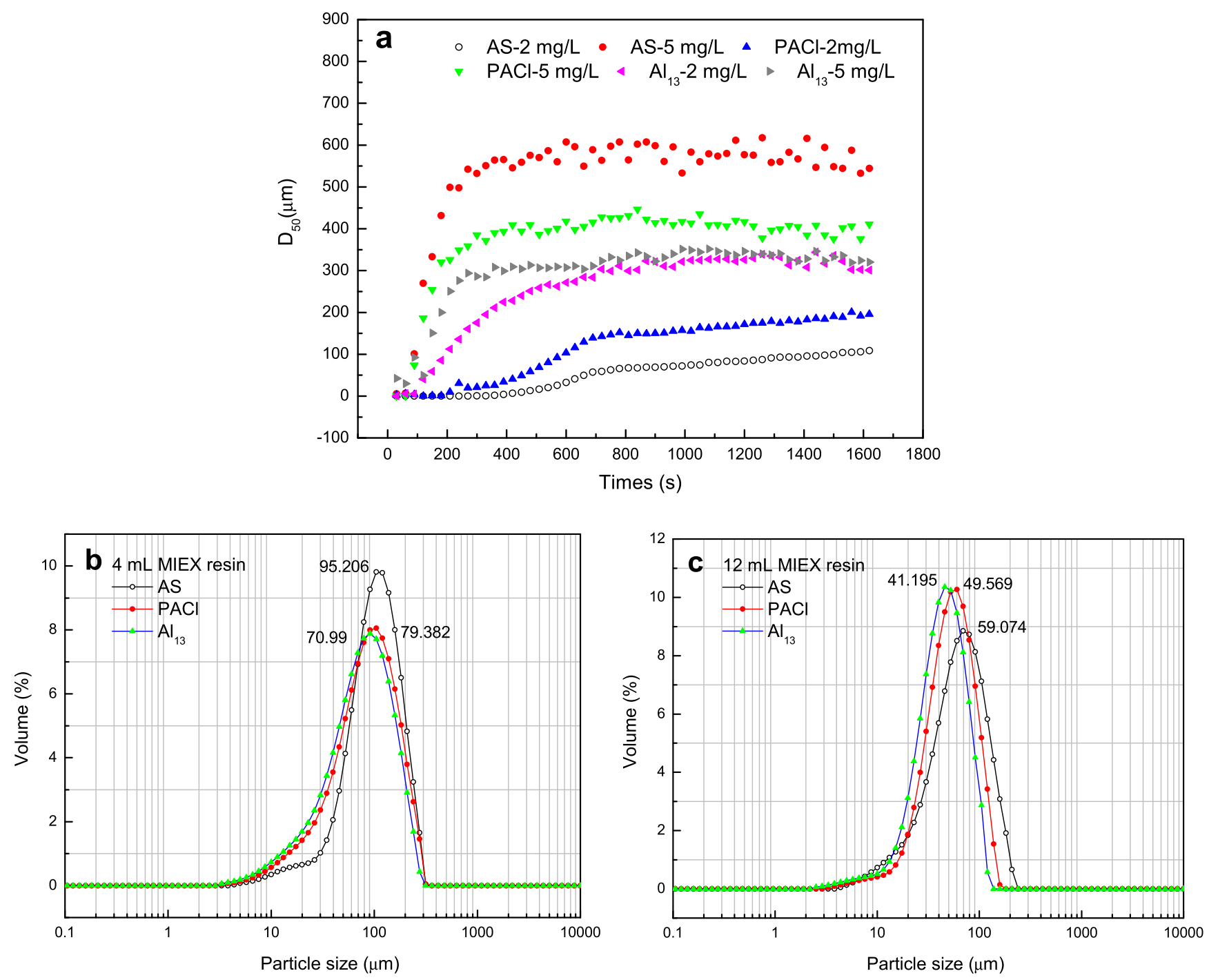

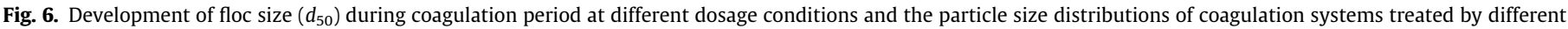
dose of MIEX pre-treatment and $5.0 \mathrm{mg} / \mathrm{L}$ of coagulants.

comparable between AS and PACl. The results implied the major mechanisms of SMX removing might be the adsorption onto the metal hydroxide precipitates rather than charge neutralization, which was fully effective in $\mathrm{Al}_{13}$ coagulation system. This could also be proved by the zeta potentials for different coagulants as exhibited in Table 2. It was obviously observed that zeta potentials for all the coagulation systems were positive and as a consequent, charge neutralization would not play effective roles in the SMX removals. Comparatively, the hydrolysis of unstable aluminum species in $\mathrm{AS}$ and $\mathrm{PACl}$, including monomeric and dimeric species, could lead to the formation of precipitated solids and probably adsorb or co-precipitate with the synthetic compound [8,36]. Basically, the doses employed in the experiments would also achieve partial, but not efficient removal of antibiotic compound with small molecular weight (MW). The observed data correlate with previous findings [37], where coagulation preferentially removed high MW hydrophobic organic acids, which are typically highly negatively charged.

Fig. 7(b) presents percentage removals of the antibiotic compound by MIEX resin under various contact time and adsorbent dosage. Compared with sole coagulation, a greater reduction of SMX was achieved by MIEX when attached equilibrium, which showed the great advantage than coagulants. Over the MIEX dosage range of $4-20 \mathrm{~mL} / \mathrm{L}$ and reaction time range of $10-$ 60 min, 35-88\% removal of SMX was attained. Greater adsorbent dosage and longer adsorption time could apparently improve the removal efficiency and the highest removal (around 88\%) was found at the dosage of $16-20 \mathrm{~mL} / \mathrm{L}$ with $60 \mathrm{~min}$ of contact time in this study. Sorption rate was initially higher due to the great availability of resin exchange sites. However, the effect of adsorption time was less significant compared with dosage. Percentage removals varied slightly with the reaction time, suggesting an instantaneous surface reaction played a major role during the adsorption instead of a slower interparticle diffusion-controlled adsorption. That was possibly due to the characteristic of SMX in the water sample and the surface adsorption sites of MIEX resin, meaning the adsorption of SMX onto MIEX resin occurred quickly after each contact. SMX is an antibiotic with $\mathrm{p} K_{\mathrm{a}}$ of 1.85 , thus it exists predominantly in anionic form under natural aquatic environments. Based on the previous work, an initial hypothesis was developed that SMX was majorly removed by ion exchange. Although previous literature [38] reported that MIEX can offer improved treatment of compounds likely to have multiple dissociated carboxylic acid groups, the data in this work implied that MIEX resin was better at removing small molecules organic matter such as SMX than HA. This was possibly due to the hydrophobic HA 

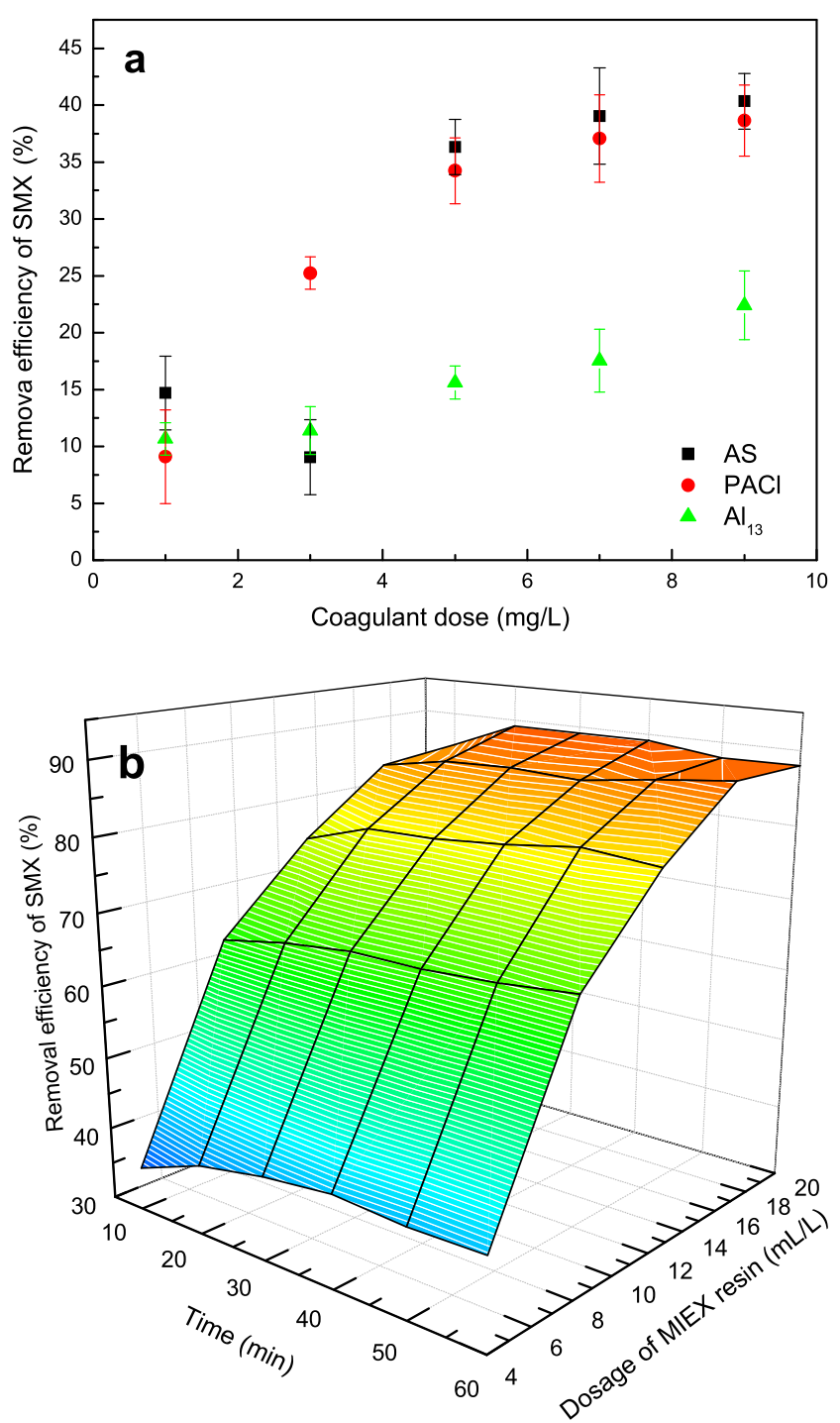

Fig. 7. Removal efficiency of SMX under (a) different dosages of various Al-based coagulants and (b) MIEX resin with different doses and contact time.

water containing higher molecular weight capable of blocking ion exchange sites.

\subsection{Effect of MIEX pre-treatment on SMX coagulation by different coagulants}

Performance of MIEX-coagulation hybrid process in SMX removal was also evaluated in this study and the result was shown in Fig. 8. As the removal efficiency varied regularly across the test dosage range for MIEX and considering the experimental purpose and cost, a low MIEX dosage of $8.0 \mathrm{~mL} / \mathrm{L}$ and $30 \mathrm{~min}$ of mixing time were selected for the MIEX coupling with coagulation process.

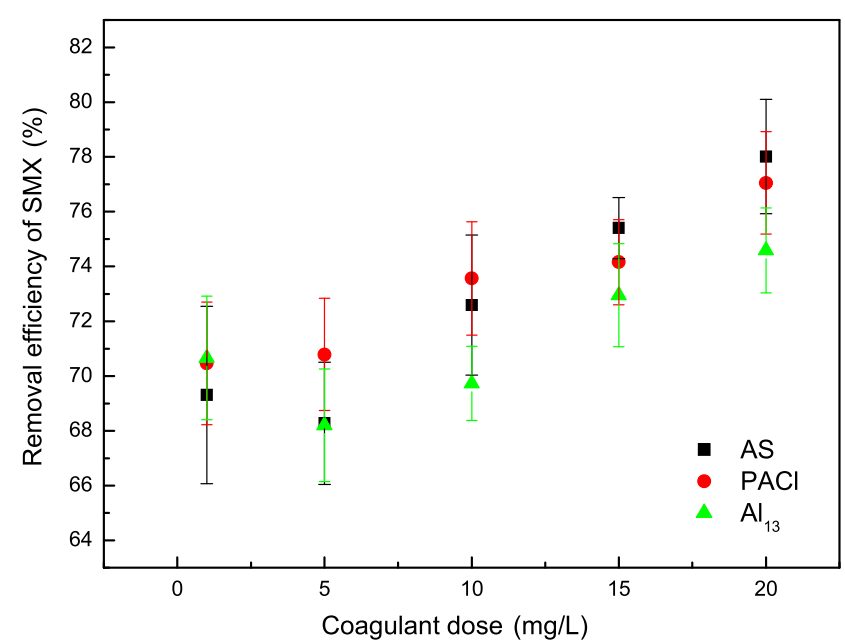

Fig. 8. The effect of coagulant dosage on coagulation couple with $8 \mathrm{~mL} / \mathrm{L}$ MIEX.

MIEX eliminated a great portion of SMX (about 67\%) according to the data in Fig. 7(b) and the subsequent coagulation could further increased the SMX removal efficiency in varying degrees. Overall, SMX removals increased with the coagulant concentration and in the dose range of $1.0-20.0 \mathrm{mg} / \mathrm{L}$, coagulations by $\mathrm{AS}, \mathrm{PACl}$ and $\mathrm{Al}_{13}$ could elevate the SMX removals to $69-78 \%, 70-77 \%$ and $68-$ $75 \%$. The efficiencies by $\mathrm{AS}$ and $\mathrm{PACl}$ seemed to be equivalent; while $\mathrm{Al}_{13}$ turned out to be inferior in coagulating the pretreated SMX waters. This agreed well with the results by single coagulation and further demonstrated charge neutralization was not supposed to function during the compound coagulation process, which could also be proved by the completely positive zeta potentials as illustrated in Table 2. Adsorption and coprecipitation of the compound and hydrolyzate played important roles in the purification process. $\mathrm{Al}_{13}$ has the most stable structure and dose not tend to hydrolyze after addition into the solution and therefore, present inferior behaviors in SMX removals. The results could also be interpreted from the point of floc sizes formed during different coagulation processes.

The dynamic floc size of SMX solution without MIEX pretreatment, presented by the median equivalent diameter $\left(d_{50}\right)$, was illustrated in Fig. 9(a). Two dosages of 5.0 and $9.0 \mathrm{mg} / \mathrm{L}$ were applied and it is evident that Al salt species is one of the most important factor influencing floc size. After continuously growth of flocs, the steady-state sizes for $\mathrm{Al}_{13}$ coagulation at 5.0 and $9.0 \mathrm{mg} / \mathrm{L}$ were around 210 and $170 \mu \mathrm{m}$, respectively; while AS and $\mathrm{PACl}$ resulted in obviously larger floc sizes after reaching the plateau. Boller and Blaser [39] declared that the small particles generally have lower solid/liquid separation efficiencies than the larger ones. It has also been claimed by Jarvis et al. [40] that smaller sizes of organic matter flocs would pose a challenge to the sedimentation process and this could explained the inferior SMX removal ability of $\mathrm{Al}_{13}$. The higher of the $\mathrm{Al}_{13}$ dosage, the smaller aggregates obtained in the steady stage. This was due to the more intense re-stabilization caused by higher $\mathrm{Al}_{13}$ dose.

Table 2

Zeta potentials under different coagulants ( $\mathrm{AS}, \mathrm{PACl}$ and $\mathrm{Al}_{13}$ ) doses in term of with and without MIEX pre-treatment.

\begin{tabular}{|c|c|c|c|c|c|c|c|}
\hline \multirow[t]{2}{*}{ SMX removal processes } & \multirow[t]{2}{*}{ Coagulants } & \multicolumn{6}{|c|}{ Zeta potentials $(\mathrm{mV})$ under different Al-based coagulants doses $(\mathrm{mg} / \mathrm{L})$} \\
\hline & & 0 & 1 & 5 & 10 & 15 & 20 \\
\hline SMX water samples without pre-treatment & $\begin{array}{l}\mathrm{AS} \\
\mathrm{Al}_{13}\end{array}$ & $\begin{array}{r}0.198 \pm 1.17 \\
-1.12 \pm 1.02\end{array}$ & $\begin{array}{l}2.98 \pm 0.99 \\
7.68 \pm 1.87\end{array}$ & $\begin{array}{r}4.3 \pm 1.42 \\
5.98 \pm 1.69\end{array}$ & $\begin{array}{l}7.22 \pm 0.82 \\
6.84 \pm 0.92\end{array}$ & $\begin{array}{r}9.00 \pm 1.49 \\
10.38 \pm 1.72\end{array}$ & $\begin{array}{r}8.11 \pm 0.80 \\
14.79 \pm 1.27\end{array}$ \\
\hline SMX water samples pre-treated by MIEX resin $(\mathrm{mL} / \mathrm{L})$ & $\begin{array}{l}\text { MIEX-AS } \\
\text { MIEX-Al }_{13}\end{array}$ & $\begin{array}{l}-0.77 \pm 1.41 \\
-1.23 \pm 1.02\end{array}$ & $\begin{array}{r}5.6 \pm 0.65 \\
6.75 \pm 0.66\end{array}$ & $\begin{array}{l}6.85 \pm 1.59 \\
8.68 \pm 1.23\end{array}$ & $\begin{array}{l}6.05 \pm 1.97 \\
6.37 \pm 1.63\end{array}$ & $\begin{array}{r}6.72 \pm 1.04 \\
11.71 \pm 0.98\end{array}$ & $\begin{array}{l}16.94 \pm 0.66 \\
21.28 \pm 2.15\end{array}$ \\
\hline
\end{tabular}



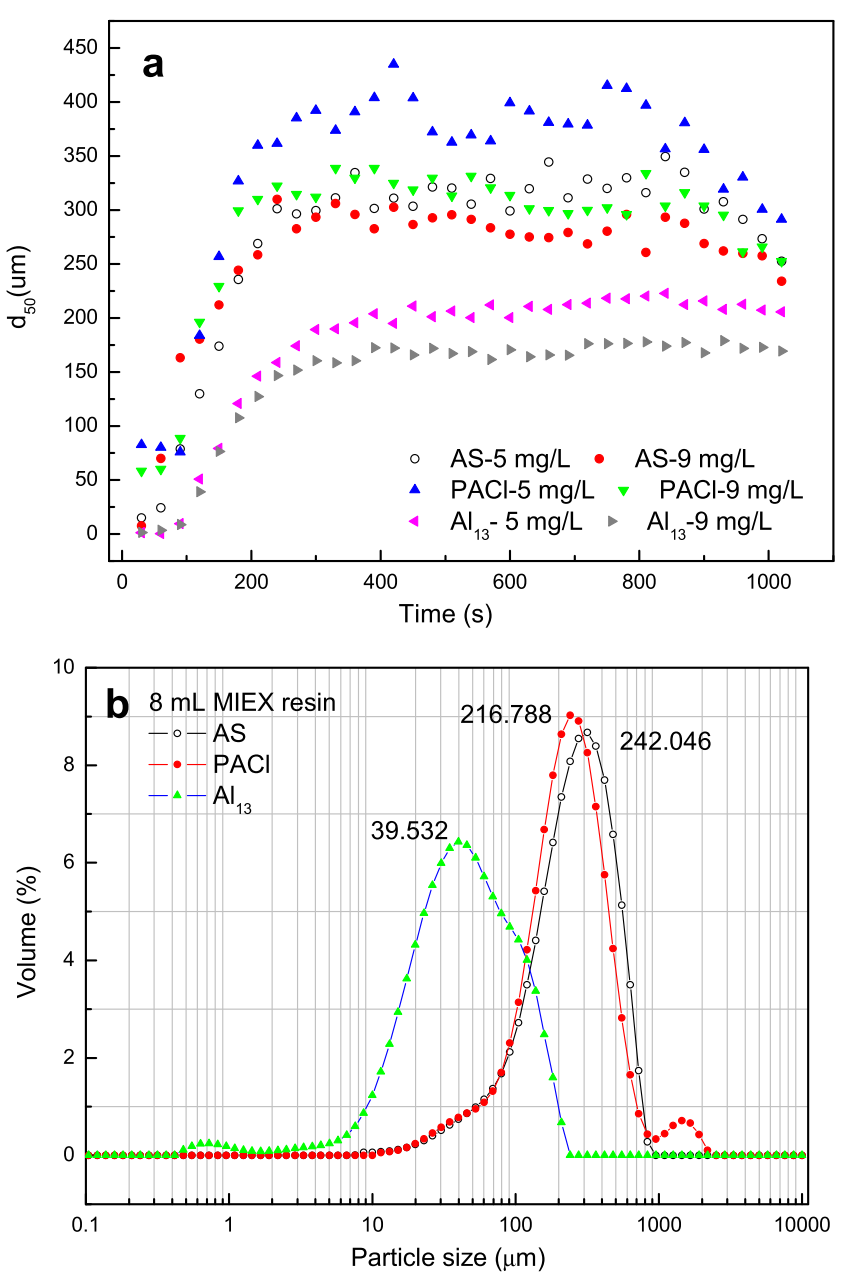

Fig. 9. The dynamic floc sizes of SMX under different coagulant dosage and the particle size distributions by MIEX $(8 \mathrm{~mL} / \mathrm{L})$ pre-treatment and various coagulants $(9.0 \mathrm{mg} / \mathrm{L})$.

Analyses of the floc particle size distributions in Fig. 9(b) illustrate a difference in the major peak by various coagulants $(9.0 \mathrm{mg} / \mathrm{L})$ after adsorption pre-treatment of $8.0 \mathrm{~mL} / \mathrm{L}$ of MIEX resin. Apparently, the average floc size became smaller compared with that without MIEX treatment. The major peaks for AS and $\mathrm{PACl}$ coagulation systems were located around 240 and $215 \mu \mathrm{m}$; while $\mathrm{Al}_{13}$ led to a considerable shift of the major peak to the left, giving rise to an average size of $40 \mu \mathrm{m}$. In combination with the data shown in Fig. 8, it could be concluded that the MIEX resin exhibited a significantly effect on floc growth, final size and the consequent SMX removal efficiency by coagulations. Furthermore, the SMX appeared to be best removed by MIEX coupled with AS/ $\mathrm{PACl}$ coagulation process, although MIEX adsorption contributed to the most reduction of compound.

\section{Conclusions}

The main conclusions of this work are:

- EC with various coagulants, although efficient in creating acceptable HA-rich water treatment, was not desirable in removal of SMX compound with small MW. Comparatively, MIEX resin was better in removing SMX through ion exchange than HA due to its higher MW capable of blocking ion exchange sites.
- For sole EC process, pre-hydrolyzed $\mathrm{PACl}$ and $\mathrm{Al}_{13}$ achieved better HA removal than AS at low dose, and charge neutralization, adsorption and sweep played important roles in HA removal. AS was best able to remove the SMX due to the adsorption or coprecipitation of compound with the hydrolyzate, which was proved to be the major coagulation mechanism in SMX removal.

- The combined use of EC/MIEX led to increases in both HA and SMX removals and consequently reduced the chemical concentration demand. Sufficient MIEX dose combined with low dose of AS, appeared to best suited to removing the organic matters with mid and high MW; while the ion exchange of MIEX plus co-precipitation of aluminum hydrolyzates could effectively improve the treatability of SMX solution.

- At moderate and high dose, $\mathrm{Al}_{13}$ contributed to the smallest floc size due to the intense charge reversal for both HA and SMX solutions; MIEX pre-treatment evidently decreased the floc size formed during the following coagulation process for all the three kinds of coagulants.

\section{Acknowledgements}

The research was supported by the National Natural Sciences Foundation of China (No. 51508226, No. 51338010, No. 51290282 and No. 51409119), the Project funded by China's Post-doctoral Science Fund (No. 2014M560126), the Scientific Technology Research and Development Program of Jinan China (Nos. TNK1408, 201401277), the Doctoral Foundation of the University of Jinan (No. XBS1405), the Chinese Academy of Science Open Fund of Key Laboratory of Drinking Water Science and Technology (No. 15K01KLDWST) and the Water Conservancy Scientific Research and Technology Promotion Projects of Shandong Province (No. SDSLKY201404).

\section{References}

[1] R. Sadiq, M.J. Rodriguez, Disinfection by-products (DBPs) in drinking water and predictive models for their occurrence: a review, Sci. Total Environ. 321 (2004) 21-46.

[2] L.P. Padhye, H. Yao, F.T. Kung'u, C.H. Huang, Year-long evaluation on the occurrence and fate of pharmaceuticals, personal care products, and endocrine disrupting chemicals in an urban drinking water treatment plant, Water Res. 51 (2014) 266-276.

[3] M. Al Aukidy, P. Verlicchi, A. Jelic, M. Petrovic, D. Barcelo, Monitoring release of pharmaceutical compounds: occurrence and environmental risk assessment of two WWTP effluents and their receiving bodies in the Po Valley, Italy, Sci. Total Environ. 438 (2012) 15-25.

[4] I. de Godos, H.O. Guzman, R. Soto, P.A. Garcia-Encina, E. Becares, R. Munoz, V.A. Vargas, Coagulation/flocculation-based removal of algal-bacterial biomass from piggery wastewater treatment, Bioresour. Technol. 102 (2011) 923-927.

[5] D. Wang, S. Wang, C. Huang, C.W.K. Chow, Hydrolyzed Al(III) clusters: speciation stability of nano-Al 13 , J. Environ. Sci. 23 (2011) 705-710.

[6] C. Feng, B. Shi, D. Wang, G. Li, H. Tang, Characteristics of simplified ferron colorimetric solution and its application in hydroxy-aluminum speciation, Colloids Surf. A 287 (2006) 203-211.

[7] D. Wang, W. Sun, Y. Xu, H. Tang, J. Gregory, Speciation stability of inorganic polymer flocculant-PACl, Colloids Surf. A 243 (2004) 1-10.

[8] M. Yan, D. Wang, J. Qu, W. He, C.W. Chow, Relative importance of hydrolyzed $\mathrm{Al}(\mathrm{III})$ species $(\mathrm{Al}(\mathrm{a}), \mathrm{Al}(\mathrm{b})$, and $\mathrm{Al}(\mathrm{c})$ ) during coagulation with polyaluminum chloride: a case study with the typical micro-polluted source waters, J. Colloid Interface Sci. 316 (2007) 482-489.

[9] B. Shi, Q. Wei, D. Wang, Z. Zhu, H. Tang, Coagulation of humic acid: the performance of preformed and non-preformed Al species, Colloids Surf. A 296 (2007) 141-148.

[10] A. Matilainen, M. Vepsalainen, M. Sillanpaa, Natural organic matter removal by coagulation during drinking water treatment: a review, Adv. Colloid Interface Sci. 159 (2010) 189-197.

[11] J.T. Alexander, F.I. Hai, T.M. Al-aboud, Chemical coagulation-based processes for trace organic contaminant removal: current state and future potential, J. Environ. Manage. 111 (2012) 195-207.

[12] M. Huerta-Fontela, M.T. Galceran, F. Ventura, Occurrence and removal of pharmaceuticals and hormones through drinking water treatment, Water Res. 45 (2011) 1432-1442. 
[13] S.D. Kim, J. Cho, I.S. Kim, B.J. Vanderford, S.A. Snyder, Occurrence and removal of pharmaceuticals and endocrine disruptors in South Korean surface, drinking, and waste waters, Water Res. 41 (2007) 1013-1021.

[14] C.J. Johnson, P.C. Singer, Impact of a magnetic ion exchange resin on ozone demand and bromate formation during drinking water treatment, Water Res. 38 (2004) 3738-3750.

[15] T.H. Boyer, P.C. Singer, Bench-scale testing of a magnetic ion exchange resin for removal of disinfection by-product precursors, Water Res. 39 (2005) 12651276.

[16] D.A. Fearing, J. Banks, S. Guyetand, C. Monfort Eroles, B. Jefferson, D. Wilson, P. Hillis, A.T. Campbell, S.A. Parsons, Combination of ferric and MIEX ${ }^{\circledR}$ for the treatment of a humic rich water, Water Res. 38 (2004) 2551-2558.

[17] J.N. Apell, T.H. Boyer, Combined ion exchange treatment for removal of dissolved organic matter and hardness, Water Res. 44 (2010) 2419-2430.

[18] K. Watson, M.J. Farré, N. Knight, Enhanced coagulation with powdered activated carbon or MIEX $^{\circledR}$ secondary treatment: a comparison of disinfection by-product formation and precursor removal, Water Res. 68 (2015) 454-466.

[19] J. Wang, H. Li, C. Shuang, A. Li, C. Wang, Y. Huang, Effect of pore structure on adsorption behavior of ibuprofen by magnetic anion exchange resins, Microporous Mesoporous Mater. 210 (2015) 94-100.

[20] C. Shuang, M. Wang, Q. Zhou, W. Zhou, A. Li, Enhanced adsorption and antifouling performance of anion-exchange resin by the effect of incorporated $\mathrm{Fe}_{3} \mathrm{O}_{4}$ for removing humic acid, Water Res. 47 (2013) 6406-6414.

[21] W. Xu, B. Gao, R. Mao, Q. Yue, Influence of floc size and structure on membrane fouling in coagulation-ultrafiltration hybrid process - the role of $\mathrm{Al}_{13}$ species, J. Hazard. Mater. 193 (2011) 249-256.

[22] W. Xu, B. Gao, Effect of shear conditions on floc properties and membrane fouling in coagulation/ultrafiltration hybrid process - the significance of $\mathrm{Al}_{\mathrm{b}}$ species, J. Membr. Sci. 415-416 (2012) 153-160.

[23] B. Shi, G. Li, D. Wang, D.S. Wang, H. Tang, Separation of $\mathrm{Al}_{13}$ from polyaluminum chloride by sulfate precipitation and nitrate metathesis, Sep. Purif. Technol. 54 (2007) 88-95.

[24] W. Yuan, A.L. Zydney, Humic acid fouling during ultrafiltration, Environ. Sci. Technol. 34 (2000) 5043-5050.

[25] P. Westerhoff, Y. Yoon, S. Snyder, E. Wert, Fate of endocrine-disruptor pharmaceutical, and personal care product chemicals during simulated drinking water treatment processes, Environ. Sci. Technol. 39 (2005) 66496663.
[26] Y. Wang, B.Y. Gao, X.M. Xu, W.Y. Xu, G.Y. Xu, Characterization of floc size strength and structure in various aluminum coagulants treatment, J. Colloid Interface Sci. 332 (2009) 354-359.

[27] J.L. Lin, C.J.M. Chin, C.P. Huang, J.R. Pan, D.S. Wang, Coagulation behavior of $\mathrm{Al}_{13}$ aggregates, Water Res. 42 (2008) 4281-4290.

[28] J.L. Lin, C. Huang, J.R. Pan, D. Wang, Effect of Al(III) speciation on coagulation of highly turbid water, Chemosphere 72 (2008) 189-196.

[29] J.L. Lin, C. Huang, C.J.M. Chin, J.R. Pan, The origin of $\mathrm{Al}(\mathrm{OH})_{3}$-rich and $\mathrm{Al}_{13}$ aggregate flocs composition in PACl coagulation, Water Res. 43 (2009) 4285 4295 .

[30] B. Bolto, D. Dixon, R. Eldridge, S. King, K. Linge, Removal of natural organic matter by ion exchange, Water Res. 36 (2002) 5057-5065.

[31] P.C. Singer, K. Bilyk, Enhanced coagulation using a magnetic ion exchange resin, Water Res. 36 (2002) 4009-4022.

[32] T.H. Boyer, P.C. Singer, Bench-scale testing of a magnetic ion exchange resin for removal of disinfection by-product precursors, Water Res. 39 (2005) 12651276.

[33] D.A. Fearing, J. Banks, S. Guyetand, E.C. Monfort, B. Jefferson, D. Wilson, et al. Combination of ferric and MIEX for the treatment of humic rich waters, Water Res. 38 (2004) 2551-2558.

[34] C.A. Biggs, P.A. Lant, Activated sludge flocculation: on-line determination of floc size and the effect of shear, Water Res. 34 (2000) 2542-2550.

[35] W.Z. Yu, J. Gregory, L. Campos, Breakage and regrowth of Al-humic flocs-effect of additional coagulant dosage, Environ. Sci. Technol. 44 (2010) 63716376.

[36] M.Q. Yan, D.S. Wang, J.R. Ni, J.H. Qu, C.W.K. Chow, H.L. Liu, Mechanism of natural organic matter removal by polyaluminum chloride: effect of coagulant particle size and hydrolysis kinetics, Water Res. 42 (2008) 3361-3370.

[37] E.L. Sharp, P. Jarvis, S.A. Parsons, B. Jefferson, Impact of fractional character on the coagulation of NOM, Colloids Surf. A: Physicochem. Eng. Aspects 286 (2006) 104-111.

[38] T. Bond, E.H. Goslan, S.A. Parsons, B. Jefferson, Disinfection by-product formation of natural organic matter surrogates and treatment by coagulation, MIEX and nanofiltration, Water Res. 44 (2010) 1645-1653.

[39] M. Boller, S. Blaser, Particles under stress, Water Sci. Technol. 37 (1998) 929.

[40] P. Jarvis, B. Jefferson, S.A. Parsons, How the natural organic matter to coagulant ratio impacts on floc structural properties, Environ. Sci. Technol. 39 (2005) 8919-8924. 